\title{
Modelling and simulation of pear drying
}

\author{
R.P.F. Guiné ${ }^{\mathrm{a}, *}$, A.E. Rodrigues ${ }^{\mathrm{b}}$, M.M. Figueiredo ${ }^{\mathrm{c}}$ \\ ${ }^{\text {a } F o o d ~ E n g i n e e r i n g ~ D e p a r t m e n t, ~ E S A V, ~ P o l y t e c h n i c ~ I n s t i t u t e ~ o f ~ V i s e u, ~ Q u i n t a ~ d a ~ A l a g o a, ~ E s t r a d a ~ d e ~ N e l a s, ~ 3500-606 ~ V i s e u, ~ P o r t u g a l ~}$ \\ ${ }^{\mathrm{b}}$ LSRE - Chemical Engineering Department, University of Porto, Rua Dr. Roberto Frias, 4200-465 Porto, Portugal \\ c Chemical Engineering Department, University of Coimbra, Pólo II, Pinhal de Marrocos, 3030-290 Coimbra, Portugal
}

To the memory of Professor José Almiro Castro

\begin{abstract}
In the present work a diffusion based model was adopted to represent the drying behaviour of pears in a continuous convective drier, taking into consideration the variation of the properties of the pears along drying.

The program developed simulated a significant number of situations resultant from the variation of some of the operating conditions. The temperatures tested were 30,40 and $50{ }^{\circ} \mathrm{C}$, the air velocities were $0.5,1.0$ and $1.5 \mathrm{~m} / \mathrm{s}$, and the relative humidity of the drying air was $40 \%, 50 \%$ and $60 \%$.

From the situations analyzed, and considering the specifications required for the final product, it was concluded that the drying should be carried out at $40{ }^{\circ} \mathrm{C}$, with a drying air velocity of $1.5 \mathrm{~m} / \mathrm{s}$ and containing $60 \% \mathrm{RH}$.
\end{abstract}

(c) 2007 Elsevier Inc. All rights reserved.

Keywords: Drying; Shrinkage; Pear; Diffusion; Fick’s law; Modelling; Simulation

\section{Introduction}

The operation of drying has been widely used to preserve food products, and fruits in particular, since the reduction of their water content to certain levels inhibits microbial growth and enzymatic modifications. Additionally, food drying presents other advantages like avoiding the need of using expensive cooling systems for preservation, or facilitating transport and storage due to the reduction in size. On the other hand, it allows the diversification of available food products, with different flavours and textures $[8,4]$.

Fruits like grapes, figs, plums, apricots and peaches have been dried over centuries, and represent an important portion of the worldwide food trade. However, more recently some other fruits have also been dried, like apples, mango, pawpaw, pineapple banana or pears. In Portugal, pears have been traditionally dried at direct open-air sun exposure, by a complex process involving many different stages: peeling, first drying on open fields (5-8 days), barrelling at shadow (2-3 days), pressing and, finally, second drying also on open fields

\footnotetext{
* Corresponding author.

E-mail address: raquelguine@esav.ipv.pt (R.P.F. Guiné).
} 


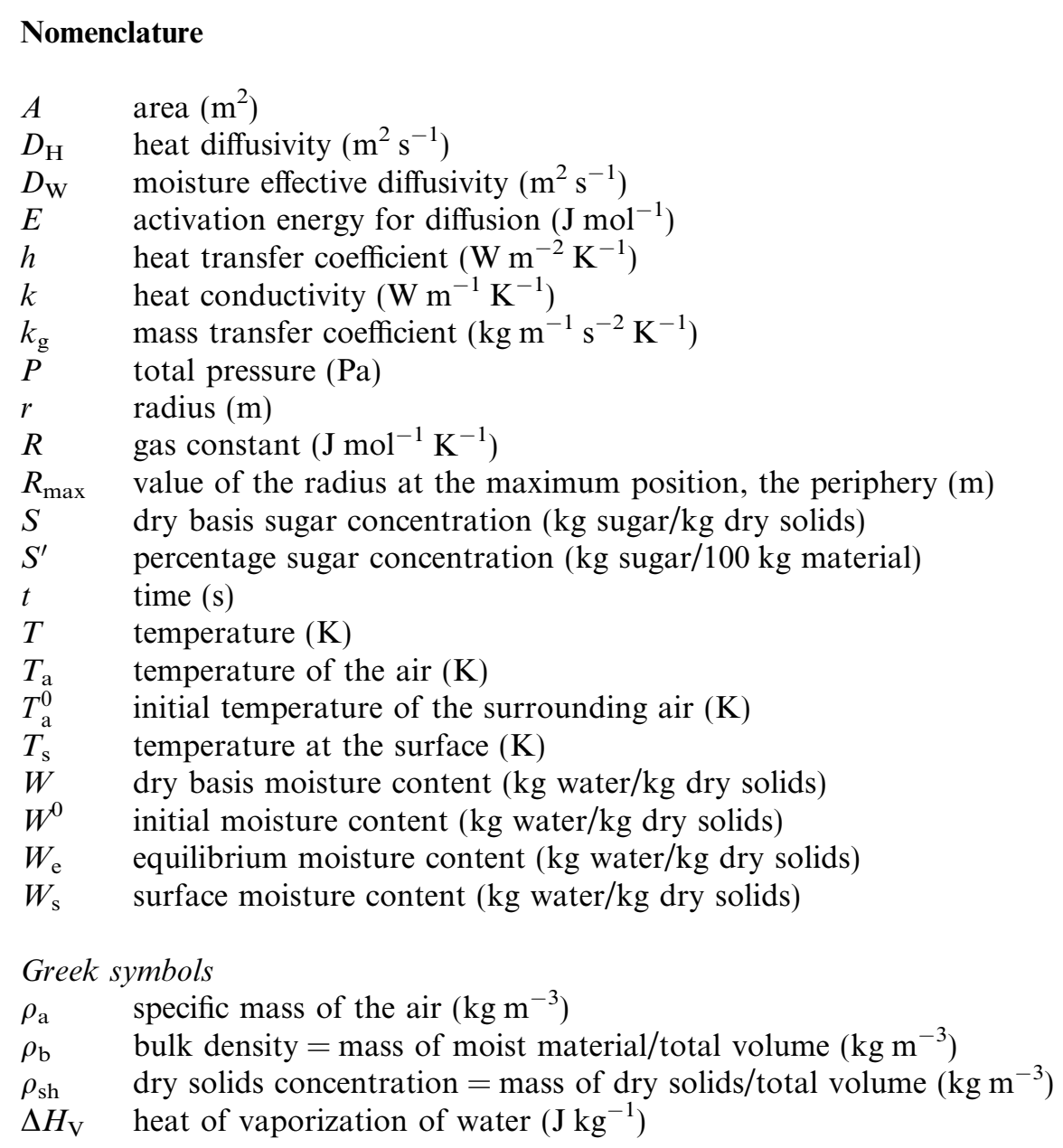

(2-3 days). Apart from the hygienic considerations, this process is very weather dependent and too expensive to be economically attractive, and that may explain why it so difficult to find this food product nowadays [5,7].

If, on the one hand, it is well recognized the importance to preserve this kind of traditional product, most appreciated for its peculiar characteristics, on the other hand it is evident the necessity of adapting the traditional drying process to an industrial scale, making it a profitable and competitive production method, offering the consumer products of unquestionable quality. This inevitably involves the process modelling and simulation and ultimately the optimization of drying conditions.

However, the modelling of food drying processes is far from simple, since these products have structures which are highly affected by the water removal [17]. Some of the models published in the literature predict the transfer phenomena occurring inside the foods during drying. However, many are solved fixing the geometric characteristics of the food (that is, neglecting shrinkage) and considering constant the transfer properties, thus leading only to approximate solutions [11]. Indeed, drying models that describe more accurately the process are difficult to obtain, mostly because transport properties (like for instance, the moisture diffusivity) are not constant, and their variation throughout the process is not available. Furthermore, the shrinking phenomena can be relatively important and are quite difficult to quantify.

Among the various theoretical models proposed in literature for the drying of foods, the diffusion models that describe the non-steady state transfer according to Fick's second law, are the most common $[1,21]$. In the present work a diffusion model is also proposed to describe the drying of pears, which accounts for shrinkage and for the variation of the transfer properties along drying. These data have been collected from experimental 
drying tests with pears. It should be pointed out, however, that this approach will increase the complexity of the models, since the diffusion equation becomes non-linear.

\section{Mathematical model}

The mathematical model proposed for the drying of pears is based on the following assumptions:

- the drying is to be carried out in an industrial dryer, that is, in a single continuous stage (the intermediate pressing operation takes place only in the end);

- the variables to be controlled are temperature, relative humidity and air velocity in the dryer;

- the pears are approximated to spheres, inside which the transfer phenomena are of diffusive nature, whereas outside only convection is considered;

- the model comprises the variation along drying of the following parameters: specific mass, specific heat, heat conductivity, heat diffusivity and mass diffusivity of water.

The model is composed of two partial differential equations, accounting for the variations of temperature $(T)$ and dry basis moisture content $(W)[9,12,13,21]$

$$
\left\{\begin{array}{l}
\frac{\partial T(r, t)}{\partial t}=\frac{1}{r^{2}}\left\{\frac{\partial}{\partial r}\left(D_{\mathrm{H}} r^{2}\left(\frac{\partial T}{\partial r}\right)\right)\right\}, \\
\frac{\partial W(r, t)}{\partial t}=\frac{1}{\rho_{\mathrm{sh}} r^{2}}\left\{\frac{\partial}{\partial r}\left(D_{\mathrm{W}} \rho_{\mathrm{sh}} r^{2}\left(\frac{\partial W}{\partial r}\right)\right)\right\} .
\end{array}\right.
$$

The corresponding initial and boundary conditions are

$$
\begin{aligned}
& \text { - at } t=0 \Rightarrow\left\{\begin{array}{l}
T(r, 0)=T(r)=T_{\mathrm{a}}^{0}, \\
W(r, 0)=W(r)=W^{0},
\end{array}\right. \\
& \text { - at } r=0 \Rightarrow\left\{\begin{array}{l}
\frac{\partial T(t)}{\partial r}=0, \\
\frac{\partial W(t)}{\partial r}=0,
\end{array}\right. \\
& \text { - at } r=R_{\max } \Rightarrow\left\{\begin{array}{l}
k A \frac{\partial T(t)}{\partial r}-\Delta H_{\mathrm{v}} D_{\mathrm{w}} \rho_{\mathrm{sh}} A \frac{\partial W(t)}{\partial r}=h A\left[T_{\mathrm{a}}(t)-T_{\mathrm{s}}(t)\right], \\
D_{\mathrm{w}} \rho_{\mathrm{sh}} A \frac{\partial W(t)}{\partial r}=k_{\mathrm{g}} A\left[W_{\mathrm{e}}(t)-W_{\mathrm{s}}(t)\right],
\end{array}\right.
\end{aligned}
$$

where, $D_{\mathrm{W}}$ is the effective diffusivity, $\rho_{\mathrm{sh}}$ is the dry solids concentration (defined as the mass of dry solids divided by total volume), $T_{\mathrm{s}}(t)$ is the surface temperature at $R_{\max }^{-}, T_{\mathrm{a}}(t)$ is the surface temperature at $R_{\max }^{+}, W_{\mathrm{s}}(t)$ is the surface moisture at $R_{\max }^{-}$and $W_{\mathrm{e}}(t)$ is the surface moisture at $R_{\max }^{+}$, given by the sorption isotherms $[19,21]$.

In the above model, the shrinkage effect is included in the variable $\rho_{\mathrm{sh}}$, since it relates the mass of dry solids to the total volume of moist material, which varies along drying [21].

\section{Process variables}

A previous experimental study was carried out to determine the variation of some model parameters along the drying of pears [6,7]. From the results obtained, it was possible to establish the time dependency of the radius as well as the variation of bulk density (defined as the mass of moist material divided by total volume) with moisture content

$$
\begin{aligned}
& R_{\max }(t)=0.0155+0.0131 \exp \left(-4.0035 \times 10^{-6} t\right), \\
& \rho_{\mathrm{b}}(W)=1079+299.6 \exp (-2.6 \mathrm{~W}),
\end{aligned}
$$

in which $R_{\max }$ is in (m), $t$ in $(\mathrm{s}), \rho_{\mathrm{b}}$ in $\left(\mathrm{kg} / \mathrm{m}^{3}\right)$ and $W$ in ( $\mathrm{kg}$ of water $/ \mathrm{kg}$ of dry solids).

The dry solids concentration, $\rho_{\mathrm{sh}}\left(\mathrm{kg} \mathrm{d} \mathrm{s} / \mathrm{m}^{3}\right)$, is related to the bulk density as

$$
\rho_{\mathrm{sh}}=\rho_{\mathrm{b}}\left(\frac{1}{1+W}\right) \text {. }
$$


For the heat transfer coefficient, it was adopted the same relationship used by Yang, Sakai and Watanabe for the drying of potato [21]

$$
N u=0.023(R e)^{0.8}(P r)^{0.4},
$$

where the numbers Nusselt, Reynolds and Prandtl refer to the air flux inside the drier.

The prediction of the mass transfer coefficient, $k_{\mathrm{g}}\left(\mathrm{kg} /\left(\mathrm{m} \mathrm{s}^{2} \mathrm{~K}\right)\right)$, was based on the following relation:

$$
\frac{h}{k_{\mathrm{G}^{\prime}} \Delta H_{\mathrm{v}}}=64.7
$$

cited by Saravacos [16], in which $k_{\mathrm{G}^{\prime}}=\frac{k_{\mathrm{g}} \rho_{\mathrm{a}}}{P}$, being $P$ the total pressure and $\rho_{\mathrm{a}}$ the specific mass of the air.

The heat conductivity and diffusivity were determined as functions of temperature using the same type of equations proposed by Choi and Okos [3], according to the chemical composition of pears, that was determined experimentally, thus obtaining the following second order polynomials:

$$
\begin{aligned}
& k(\mathrm{~W} / \mathrm{m} \cdot \mathrm{K})=1.6293 \times 10^{-1}+1.0728 \times 10^{-3} T-3.2762 \times 10^{-6} T^{2}, \\
& D_{\mathrm{H}}\left(\mathrm{m}^{2} / \mathrm{s}\right)=6.5408 \times 10^{-2}+4.2010 \times 10^{-4} T-1.8381 \times 10^{-6} T^{2} .
\end{aligned}
$$

The determination of the effective diffusion coefficient $\left(D_{\mathrm{W}}\right)$ was based on the model suggested by Zogzas et al. [14]; Zogzas, (1996), in which the dependency of the diffusivity with temperature and moisture content is expressed by a modified Arrhenius relationship. However, in the present study, that relationship has been modified in order to account for the dependency of the sugar concentration, expressed by the term $1 /(1+C S)$. In fact, the pears are very rich in sugars and their concentration rapidly increases with drying, creating asymmetries in the sugar profiles from the centre to the border [5].

$$
D_{\mathrm{W}}=D_{0} * \frac{(1+B W)}{(1+C S)} *\left[\exp \left(-\frac{E}{R T}\right)\right] .
$$

In the above equation $W$ and $S$ represent the dry basis moisture and sugar concentrations, respectively, $R$ is the gas constant $(R=8.31451 \mathrm{~J} / \mathrm{mol} \mathrm{K}), T$ is absolute temperature. The parameters $\left(D_{0}, B, C, E\right)$ were estimated from experimental data using an orthogonal regression algorithm: $D_{0}=1.1276 \times 10^{-5}\left(\mathrm{~m}^{2} / \mathrm{s}\right)$, and represents the diffusivity for an infinite temperature, $B=1.2987 \times 10^{-2}, C=4.5111 \times 10^{-1}, E=2.4313 \times 10^{4}$ $(\mathrm{J} / \mathrm{mol})$ and represents the activation energy for diffusion. The value of $E(24.3 \mathrm{~kJ} / \mathrm{mol})$ is in agreement with the findings of other authors (between 15 and $95 \mathrm{~kJ} / \mathrm{mol}$ ), reported for different food products $[10,14,15]$.

\section{Results and discussion}

The model developed was solved for different process conditions, using the software package developed by Stewart, Caracotsios and Sorensen [18] named PDASAC, which is capable of solving mixed systems of partial differential equations and algebraic equations.

- The temperatures tested were 30,40 and $50{ }^{\circ} \mathrm{C}$, since this range allows the preservation of the fruits attributes, either sensorial or nutritional, according to the data obtained experimentally from drying pears under different temperatures;

- the values of the relative humidity of the drying air investigated were $40 \%, 50 \%$ and $60 \%$, to favour a smooth drying, thus preserving the structure of the fruits and therefore their texture properties;

- the air velocities analysed were $0.5,1.0$ and $1.5 \mathrm{~m} / \mathrm{s}$, because they are frequently cited by many authors in drying studies $[2,20]$.

The simulations were terminated when the radial mean value of the moisture content reached $20 \%$, since this is the optimum value for this kind of dried fruit, taking into consideration the required physical and chemical properties [5].

From all the drying conditions tested, a selection was made taking only into account processes finished in about 5 or 6 days. This period was chosen because it represents a compromise between two factors: the time to 


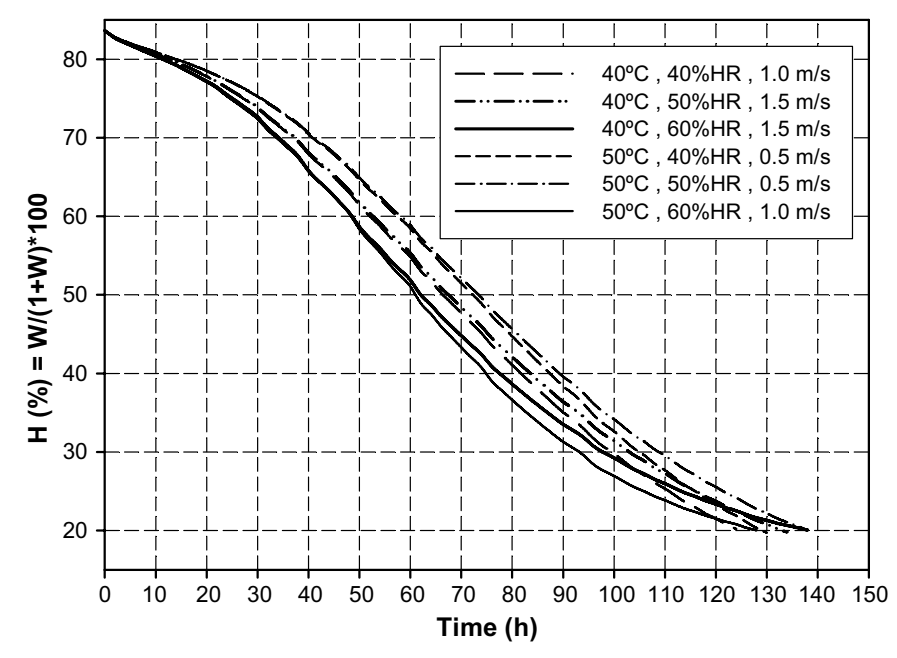

Fig. 1. Drying curves for the cases in which the total drying time is 5-6 days.

approach the characteristics of the traditional solar dried pears (e.g. fruit oxidation) and the economic viability of the process. Thus, from the 27 situations tested in only six cases (shown in Fig. 1) the drying time (meaning the time necessary for the mean value of the moisture content to reach approximately $20 \%$ ), was situated between 120 and $144 \mathrm{~h}$.

From the drying curves presented in Fig. 1, the one selected was that corresponding to the air drying conditions of $40{ }^{\circ} \mathrm{C}$ with $60 \%$ relative humidity and $1.5 \mathrm{~m} / \mathrm{s}$ circulating velocity. The reasons that support this choice are the following: (a) low temperatures minimize the eventual degradation of sugars and proteins; (b) high air velocities favour the oxidation and the darkening of the surface of the pears (thus compensating for the shortening of the process when compared to the solar drying); and (c) this situation is characterised by a higher moisture loss at the initial stages and a tendency for stabilization at the final stage, similar to the behaviour experimentally observed.

The characterization of the process for the selected case is summarised in two figures showing the variations along time and along the radial position of the process variables: temperature (T) (Fig. 2) and moisture content $\left(H\right.$, in \%) (Fig. 3). A third variable, sugar concentration $\left(S^{\prime}\right)$, not explicit in the model but tightly con-

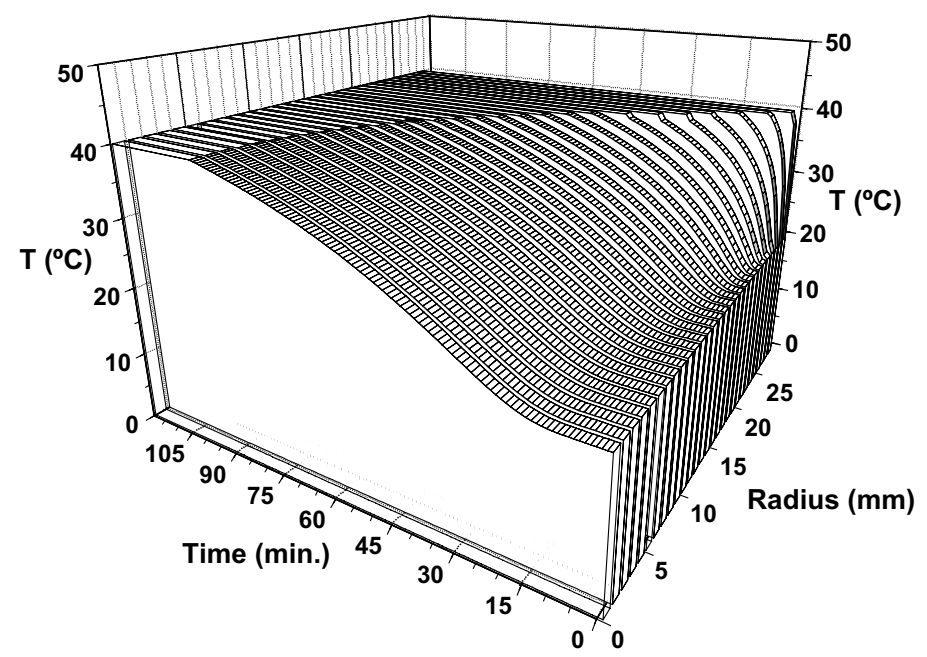

Fig. 2. Variations of temperature $(T)$ in space and time, for the selected case $\left(40{ }^{\circ} \mathrm{C}, 60 \% H R, 1.5 \mathrm{~m} / \mathrm{s}\right)$. 


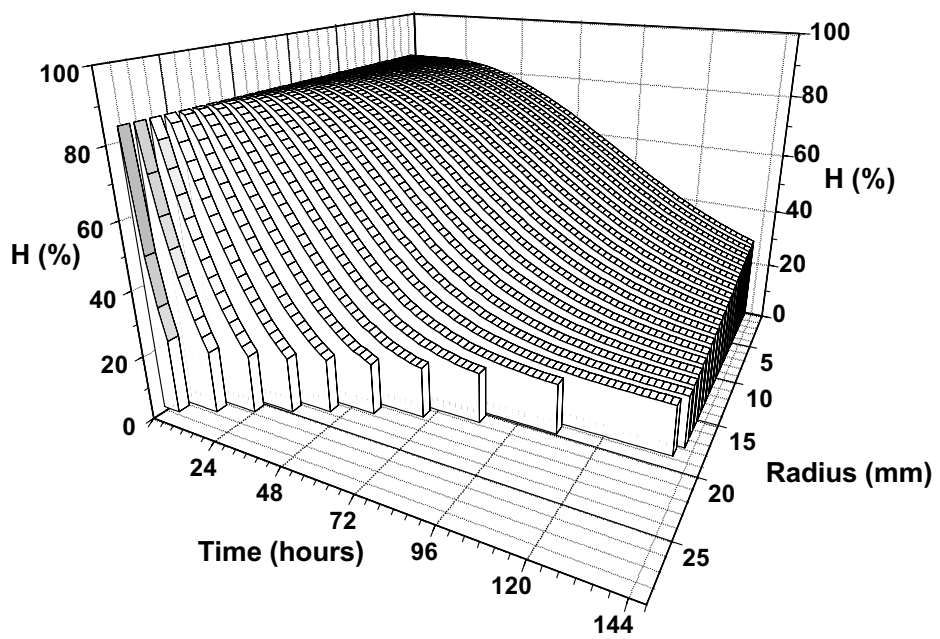

Fig. 3. Variations of moisture concentration $(H)$ in space and time, for the selected case $\left(40{ }^{\circ} \mathrm{C}, 60 \% H R, 1.5 \mathrm{~m} / \mathrm{s}\right)$.

nected to the model variable moisture content, is also illustrated (Fig. 4). The sugar concentration, $S^{\prime}$, expressed in \%, is related to the dry basis sugar content $(S)$ and the dry basis moisture content $(W)$ by

$$
S^{\prime}(\%)=100 * \frac{S}{1+W} .
$$

From Fig. 2, which depicts the variation of temperature with $r$ and $t$, it is possible to observe that the increase in temperature is very fast in the peripherical positions, being slower in the centre, where the paths for heat transfer are longer, as expected. This graph also shows that every point inside the pears reaches the outside temperature $\left(40{ }^{\circ} \mathrm{C}\right)$ before $2 \mathrm{~h}$. Both Figs. 3 and 4 clearly display the shrinking effect, with the pear radius varying from a maximum of $28 \mathrm{~mm}$ to a minimum of $18 \mathrm{~mm}$. In Fig. 3 it is also evident that the moisture content decrease is faster in the periphery, close to the evaporation front, when compared to the centre. This behaviour is totally opposite to that of sugar evolution illustrated in Fig. 4, in which a very fast increase in sugar concentration close to the border was found, making difficult the water diffusion. This behaviour has

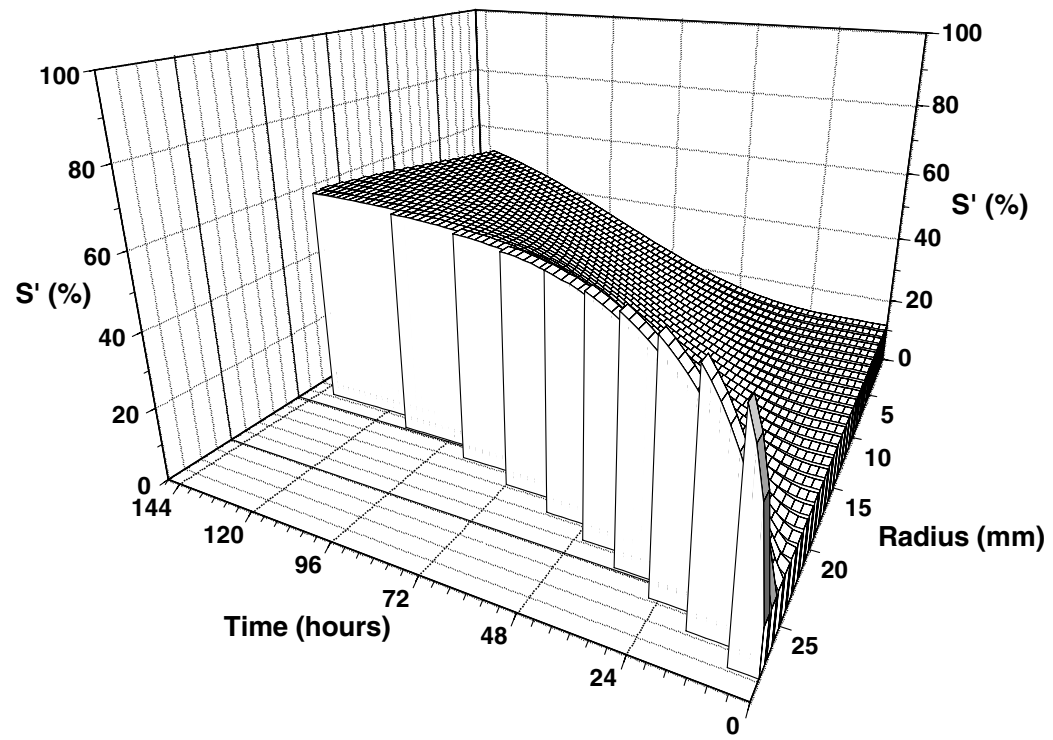

Fig. 4. Variations of sugar concentration $\left(S^{\prime}\right)$, for the selected case $\left(40{ }^{\circ} \mathrm{C}, 60 \% H R, 1.5 \mathrm{~m} / \mathrm{s}\right)$. 
been observed experimentally [5], and was expected since the evaporation of water directly contributes for the concentration of the sugars present in the fruit.

The variations of moisture concentration in space and time are presented in a more understandable way (in the form of bi-dimensional curves) in Figs. 5 and 6. The former represents the evolution of moisture $(H)$ with time for different radial positions, and confirms that at the periphery the profile is far much steeper (corresponding to a very fast drying rate) than in the centre, where a smooth sigmoid curve was obtained (as a result of the paths for moisture diffusion being longer and more tortuous). The values of the final moisture concentration are around $20 \%$, as it was defined by the stopping criteria, and are obtained earlier in the peripheral positions and only later in the interior parts. In Fig. 6, different radial profiles of moisture concentration are plotted for different times, being clear that after $8 \mathrm{~h}$ of drying no variations are observed in the centre of the pear but contrasting with the sharp variation found in the border. At $48 \mathrm{~h}$ the variations are extended to the centre of the pear and consequently the radial moisture profile starts to smooth out. At the end of drying (after $144 \mathrm{~h}$ ) the profile obtained is linear, with moisture concentrations varying from approximately $15 \%$ in the

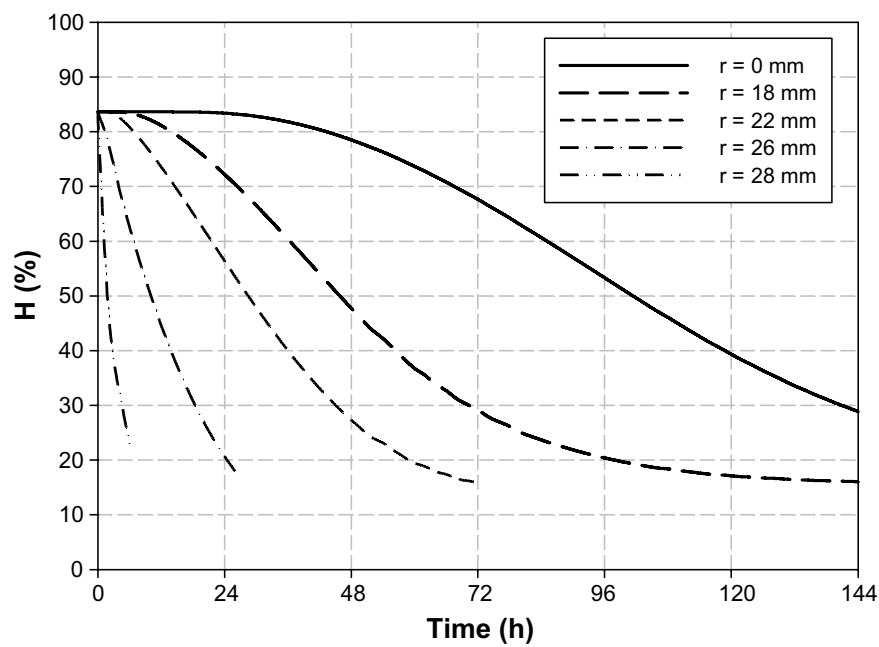

Fig. 5. Evolution of moisture concentration along time, for different radial positions $\left(40{ }^{\circ} \mathrm{C}, 60 \% H R, 1.5 \mathrm{~m} / \mathrm{s}\right)$.

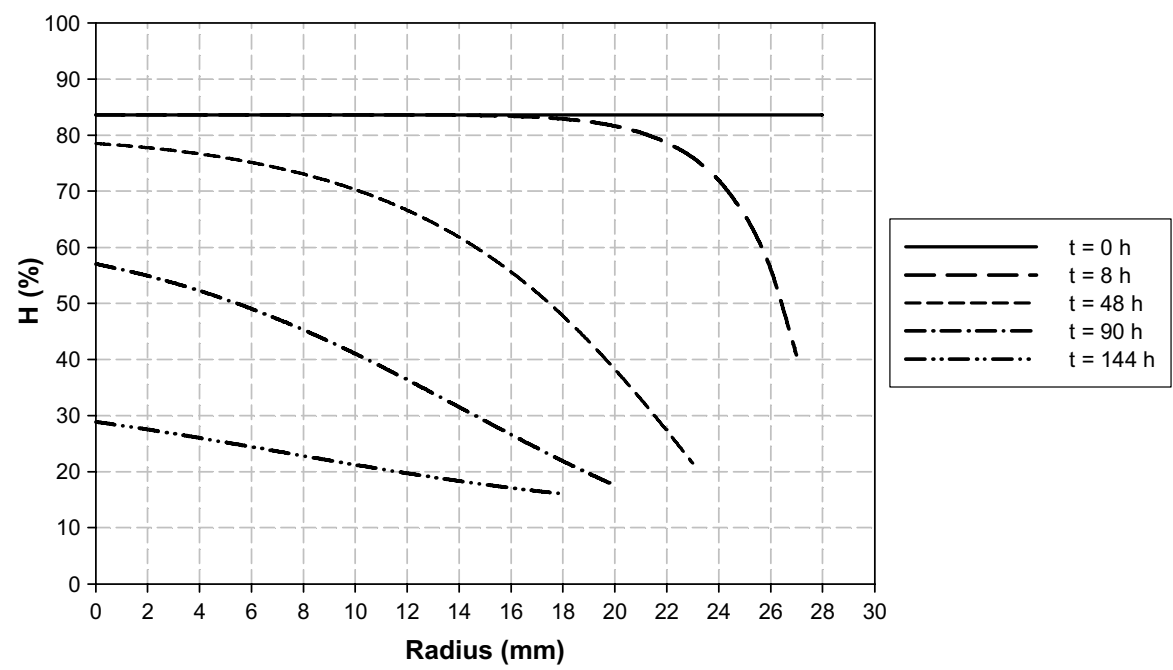

Fig. 6. Radial profiles of moisture concentration for different times $\left(40{ }^{\circ} \mathrm{C}, 60 \% \mathrm{HR}, 1.5 \mathrm{~m} / \mathrm{s}\right)$. 


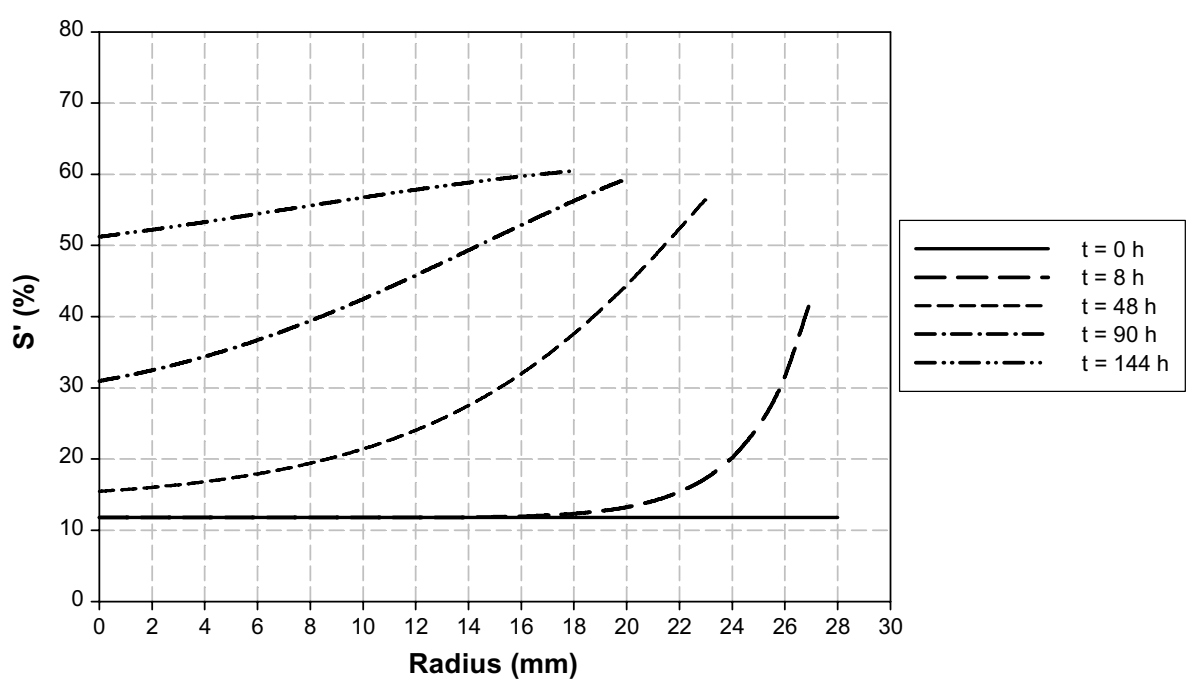

Fig. 7. Radial profiles of sugar concentration for different times $\left(40^{\circ} \mathrm{C}, 60 \% H R, 1.5 \mathrm{~m} / \mathrm{s}\right)$.

periphery to $28 \%$ in the centre, resulting in the radial mean value of $20 \%$. Furthermore, this figure clearly evidences the reduction in pear dimensions throughout the drying process.

Different radial profiles of sugar concentration predicted by the model are also represented, as a function of time, in Fig. 7. As expected, the evolution of the radial sugar concentration profiles with time is opposite to that of moisture content (Fig. 6), exhibiting a steep increase at the periphery (from $11 \%$ to $42 \%$ in only $8 \mathrm{~h}$ ), without changing the concentration in the centre. The curves change progressively until the end (happening after $144 \mathrm{~h}$ ) when a linear profile is obtained, with concentrations varying from $52 \%$ to $61 \%$.

The results obtained with this simulation are in some accordance with the behaviour observed experimentally for dried pears by Guiné and Castro [5].

\section{Conclusions}

From the present work, a drying model to describe the drying behaviour of pears was established. The predicted drying curves and the temperature and moisture distributions compare favourably with the results previously obtained experimentally. This model includes the effect of shrinking, which, in the present case, is very significant (almost 40\%).

Furthermore, from the cases studied and taking into account the specifications of the product (as close as possible to the solar dried pears) it was concluded that the best drying conditions correspond to a drying temperature of $40{ }^{\circ} \mathrm{C}$, with the drying air at $1.5 \mathrm{~m} / \mathrm{s}$, and containing $60 \% \mathrm{RH}$.

\section{References}

[1] C. Bonazzi, A. Ripoche, C. Michon, Moisture diffusion in gelatin slabs by modeling drying kinetics, Drying Technology 15 (6-8) (1997) 2045-2059.

[2] W.-C. Chiang, J.N. Peterson, Experimental measurement of temperature and moisture profiles during apple drying, Drying Technology 5 (1) (1987) 25-49.

[3] Y. Choi, M.R. Okos, Effects of Temperature and Composition on the Thermal Properties of Foods in Food Engineering and Process Applications: Transport Phenomena, vol. 1, Elsevier Applied Science Publishers, Belfast, 1986.

[4] R. Earle, Unit Operations in Food Processing, second ed., Pergamon Press, Ltd., Oxford, 1988.

[5] R.P.F. Guiné, J.A.A.M. Castro, Pear drying process analysis: drying rates and evolution of water and sugar concentrations in space and time, Drying Technology 20 (7) (2002) 1515-1526.

[6] R.P.F. Guiné, J.A.A.M. Castro, Experimental determination and computer fitting of desorption isotherms of D. Joaquina pears, Food and Bioproducts Processing: Trans IChemE, Part C 80 (C3) (2002) 149-154.

[7] R.P.F. Guiné, J.A.A.M. Castro, Analysis of moisture content and density of pears during drying, Drying Technology 21 (3) (2003) 581-591. 
[8] H. Hayashi, Drying technologies of foods - their history and future, Drying Technology 7 (2) (1989) 315-369.

[9] P.J.A.M. Kerkhof, Drying, growth towards a unit operation, Drying Technology 19 (8) (2001) 1505-1541.

[10] Y. Konishi, J.-I. Horiuchi, M. Kobayashi, Dynamic evaluation of the dehydration response curves of food characterized by a poultice-up process using a fish-paste sausage. I. Determination of the mechanisms for moisture transfer, Drying Technology 19 (7) (2001) 1253-1269.

[11] J.Y. Liu, W.T. Simpson, Solutions of diffusion equation with constant diffusion and surface emission coefficients, Drying Technology 15 (10) (1997) 2459-2477.

[12] M.D. Matteo, L. Cinquanta, L. Galiero, S. Crescitelli, A mathematical model of mass transfer in spherical geometry: plum (Prunus Domestica) drying, Journal of Food Engineering 58 (2003) 183-192.

[13] P. Perré, B.K. May, A numerical drying model that accounts for the coupling between transfers and solid mechanics. Case of highly deformable products, Drying Technology 19 (8) (2001) 1629-1643.

[14] L.A. Ramallo, J.J. Pokolenko, G.Z. Balmaceda, M.F. Schmalko, Moisture diffusivity, shrinkage, and apparent density variation during drying of leaves at high temperatures, International Journal of Food Properties 4 (1) (2001) 163-170.

[15] S.S.H. Rizvi, Thermodynamic Properties of Foods in Dehydration in Engineering Properties of Foods, Marcel Dekker, New York, 1986.

[16] G.D. Saravacos, Mass Transfer Properties of Foods in Engineering Properties of Foods, Marcel Dekker, New York, 1986.

[17] L. Saravia, V. Passamai, Relationship between a solar drying model of red pepper and the kinetics of pure water evaporation (I), Drying Technology 15 (5) (1997) 1419-1432.

[18] W.E. Stewart, M. Caracotsios, J.P. Sorensen, PDASAC Software Package Documentation, 1994.

[19] D.W. Sun, J.L. Woods, Simulation of the heat and moisture transfer process during drying in deep grain beds, Drying Technology 15 (10) (1997) 2479-2508.

[20] I.T. Togrul, D. Pehlivan, Modelling of drying kinetics of single apricot, Journal of Food Engineering 58 (2003) $23-32$.

[21] H. Yang, N. Sakai, M. Watanabe, Drying model with non-isotropic shrinkage deformation undergoing simultaneous heat and mass transfer, Drying Technology 19 (7) (2001) 1441-1460. 